\title{
Glycerol/lemon juice/based green superabsorbent hydrogel cross-linked with maleic acid
}

\author{
Titus M. Kasimu ${ }^{1}$, Harun M. Mbuvi ${ }^{1}$, Francis M. Maingi ${ }^{2 *}$ \\ ${ }^{1}$ Department ofChemistry, Kenyatta University Nairobi, Kenya ${ }^{2}$ Department of Science Technology and Engineering, Kibabii University Bungoma, Kenya
}

(Received: November 10, 2021; Revised: December 27, 2021; Accepted: December 29, 20211; Published: January 14, 2022)

*Corresponding author: mukoramaingi@yahoo.com)

\begin{abstract}
Superabsorbent hydrogels continue to be very important materials due to their applications in several technologies. Unfortunately, most superabsorbent hydrogels currently on the market are acrylate-based products that are non-biodegradable, and, most importantly, some concerns exist about their toxicity for use in agriculture. This study aimed at synthesizing and characterizing biocompatible superabsorbent hydrogel derived from lemon juice. The process involved polymerizing lemon juice (LJ) with glycerol (G) monomers to form polymeric material (HLG-1). HLG-1 was then converted to HLG-2 by crosslinking with maleic acid. Characterization of the hydrogels was done using Fourier transform infrared (FT-IR) spectroscopy, scanning electron microscope (SEM), and X-ray diffraction (XRD). The synthesis conditions producing optimal swelling capacity were studied by varying contact time and dosage of both lemon juice and the cross-linker. The FT-IR results showed a peak at $1528 \mathrm{~cm}^{-1}$ and $1591.34 \mathrm{~cm}^{-1}$ associated with -COO- stretching indicating successful polymerization and crosslinking processes. XRD analysis showed conversion from amorphous to crystalline phases upon crosslinking. SEM micrographs showed clear pores with large surface area in HLG-2 compared with the rigid and constricted surface of HLG-1 hydrogel. A maximum swelling capacity of 910\% was obtained upon synthesizing hydrogel HLG-2 with lemon juice, glycerol, and maleic acid of a volume ratio of 5.4: 3.75: 3.75 respectively. Crosslinking the hydrogel with maleic acid was found to improve the water absorption capacity of the hydrogel. The superabsorbent hydrogel with such high swelling and water absorption ability has the potential of being applied in arid and semi-arid regions to boost agricultural production.
\end{abstract}

Key words: Lemon juice, Characterization, Crosslinking, Glycerol, Superabsorbent hydrogel

\section{INTRODUCTION}

Superabsorbent hydrogels are three-dimensional polymeric materials with the ability to swell and retain large quantities of water within their hydrophilic structure (Koetting et al., 2015; Ullah et al., 2015). The presence of hydrophilic groups in their structure, permeability, and compatibility, makes them find application in wastewater treatment, agriculture and food industry, biotechnological and medical fields. The increase in their demand has led to increased motivation for their further study by most researchers (Rimmer, 2011). The nature of the cross-linker used determines the permanent and reversible nature of hydrogels. This is attributed to the fact that the type of cross-linker determines whether the interaction will be a chemical or involve a physical entanglement (Shukla et al., 2012). The reversible hydrogel has a non-homogeneous network as a result of non-covalent bonds and temporary chain entanglements (Shukla et al., 2012). Currently, most hydrogels in the market are synthetic acrylate-based products, and their application is limited due to poor biocompatibility and nonbiodegradability and hence toxic when applied in agriculture (Meng \& Ye, 2017). This study was therefore geared towards synthesizing superabsorbent hydrogels that are non-toxic, biocompatible, and biodegradable by incorporating glycerol organic surfactant into lemon juice in the presence of maleic acid as a cross-linker with a view of addressing the technical limitations posed in the existing hydrogels.

\section{MATERIALS AND METHODS}

\section{Reagents and chemicals}

The lemons were purchased from a local market in Machakos County-Kenya and were used as the source of citric acid (Lemon juice). Glycerol was purchased from Merck Chemical Co (Darmstadt, Germany), while maleic acid was obtained from Sigma Aldrich Company (German).

\section{Extraction of lemon juice (LJ) from lemons}

The lemons were washed with distilled water to remove earthy materials and then peeled to obtain the soft part. The soft part was cut into smaller pieces and blended using an electric blender (CSZ 910) to obtain a viscous mixture. The mixture was then filtered using a standard sieve of 14-16 micro pores to obtain lemon juice (LJ) (Coolman et al., 2008).

\section{Preparation of hydrogel using lemon juice and ethylenediamine (HLG-1)}

$72.0 \mathrm{~mL}$ of lemon juice and $45.0 \mathrm{~mL}$ of $13.6 \mathrm{M}$ glycerol were measured and put into a $2-\mathrm{L}$ aluminum container. 
The mixture was then heated in an oven at a temperature of $373 \mathrm{~K}$ while stirring to facilitate the polymerization reaction. The heating was stopped when the viscous gel was formed and the gel cooled to form clear solid (HLG-1) hydrogel (Coolman et al., 2008).

\section{Crosslinking of the polymer gel HLG-1 with maleic acid}

The hydrogel gel HLG-1 prepared in section 2.3 was cut into smaller pieces and placed in a $2 \mathrm{~L}$ aluminum container and heated in an oven to melt. $50.0 \mathrm{~mL}$ of $3.5 \mathrm{M}$ maleic acid was then added as a cross-linker and the mixture was heated continuously with stirring at a temperature of $373 \mathrm{~K}$ until a viscous gel was formed. The mixture was then removed from the oven and cooled to form (HLG-2) hydrogel. Figure 1 shows the diagrammatic scheme for preparation of HLG-2 hydrogel.

\section{Characterization of the hydrogel}

\section{FT-IR analysis of the superabsorbent hydrogels}

The FTIR spectroscopy technique was used to analyze structural changes of HLG-1 and HLG-2 hydrogels before and after crosslinking. Crystal of the synthesized samples was dried in an oven at $45^{\circ} \mathrm{C}$ until a constant weight was attained (Selling et al., 2015). $1 \mathrm{mg}$ of each of the hydrogel samples was mixed with $25 \mathrm{mg}$ of dry spectroscopic grade potassium bromide. The mixture was then ground with a mortar and pestle to form a fine powder which was compressed into a thin transparent pellet for analysis using FT-IR (model Shimadzu IR Tracer-100) at a wavelength range of 4000-200 $\mathrm{cm}^{-1}$ (Hammond et al., 2005).

\section{XRD analysis of the superabsorbent hydrogels}

The phase compositions analysis procedure of the (HLG-1 and HLG-2) hydrogels was adopted from Aikawa et al. (1998). Dried hydrogel samples were cut into smaller sizes before placing them into the silicon wafer. The determination of phase and morphology of samples was taken continuously from scattering angle $(2 \theta)$ ranging 10 to $90^{\circ}$ and at $40 \mathrm{kV}$ and a current of $15 \mathrm{~mA}$ with $\mathrm{Cu}$ ka radiation (1.54059-1.54441) using XRD (model Hossein Beygin German).

\section{Microstructural analysis of the superabsorbent hydrogels}

Scanning electron micrographs were used to determine the microstructure of (HLG-1 and HLG-2) superabsorbent hydrogels. The samples were oven-dried at $318 \mathrm{~K}$ for 4 hours until a constant weight was attained. The samples were goldsputter coated to make them electrically conductive then micrographs were obtained at an accelerating voltage of $2.50 \mathrm{kV}$ using a scanning electron microscope (SEM) (Zeiss Supra 60, German) (Zhu et al., 2017).

\section{Effect of lemon juice (LJ) dosage on the swelling capacity of HLG-2 hydrogel}

The superabsorbent hydrogels were prepared by varying dosage of $\operatorname{LJ}$ from $(0.9,1.8,3.6,5.4,7.2$, and $9.0 \mathrm{~mL})$ while maintaining the volumes of $13.6 \mathrm{M}$ glycerol and $3.5 \mathrm{M}$ maleic acid cross-linker as $3.75 \mathrm{~mL}$ and $5.0 \mathrm{~mL}$ respectively. The swelling ability was determined by immersing $2.0 \mathrm{~g}$ of each prepared hydrogel sample in $500 \mathrm{~mL}$ of deionized water in a $1 \mathrm{~L}$ beaker for 24 hours.

\section{Effect of maleic acid dose on the swelling capacity of the hydrogel HLG-2}

The superabsorbent hydrogels were prepared by varying dosage of the maleic acid (cross-linker) dosage (1.25, 2.5, 3.75, $5.0,6.25$, and $7.5 \mathrm{~mL}$ ) while maintaining the volume of LJ at $5.4 \mathrm{~mL}$ and that of glycerol as $3.75 \mathrm{~mL}$. The swelling capacity of hydrogels was determined by immersing $2.0 \mathrm{~g}$ of each prepared sample in distilled water for 24 hours.

\section{Equilibrium Water Content (EWC)}

The procedure for the determination of the equilibrium water content of the hydrogels was adopted from Dalaran et al. (2009). The prepared samples were allowed to dry in an oven to a constant weight at a temperature of $318 \mathrm{~K} .20 \mathrm{~g}$ of the dried sample was put in polyester-bags made of 200 mesh nylon and its weight was recorded as Mx. The samples in polyester bags were then immersed in deionized water at room temperature for 12 hours. The swollen polyester -bag was then removed from the water and wrapped with tissue paper to dry. It was then weighed and its mass recorded as Mt. The equilibrium swelling capacity was determined using equation 1 (Dalaran et al., 2011; Çöle et al., 2013).

$$
\operatorname{EWC}(\%)=\frac{M_{\mathrm{t}}-M_{x}}{M_{x}} \times 100
$$

Where $M_{x}$ initial weight of hydrogel before swelling and $M_{t}$ final mass swollen hydrogel.

\section{Effect of contact time on the swelling capacity of the hydrogel}

The effect of contact time on swelling capacity of hydrogels HLG-2 was studied by varying contact times $(0.5,1,2,4$, 6,12 , and 24 hours). $2.0 \mathrm{~g}$ of each hydrogel prepared at the optimum volume ratio of LJ: G: maleic acid of 5.4: 3.75: 3.75 was immersed in $500 \mathrm{~mL}$ of deionized water in a $1 \mathrm{~L}$ beaker for a specified contact time. After the expiry of contact time, samples were removed and the weight of swollen gel recorded followed by determination of the swelling capacity using equation 1 provided in section 2.8 .

\section{RESULTS AND DISCUSSION}

\section{FT-IR functional groups analysis of HLG-1 and HLG-2 hydrogels}

FT-IR analysis was carried out to identify the functional groups present in the superabsorbent hydrogel before and after cross-linking. Figure 2 shows the IR spectrum of the uncross-linked hydrogel (HLG-1). 


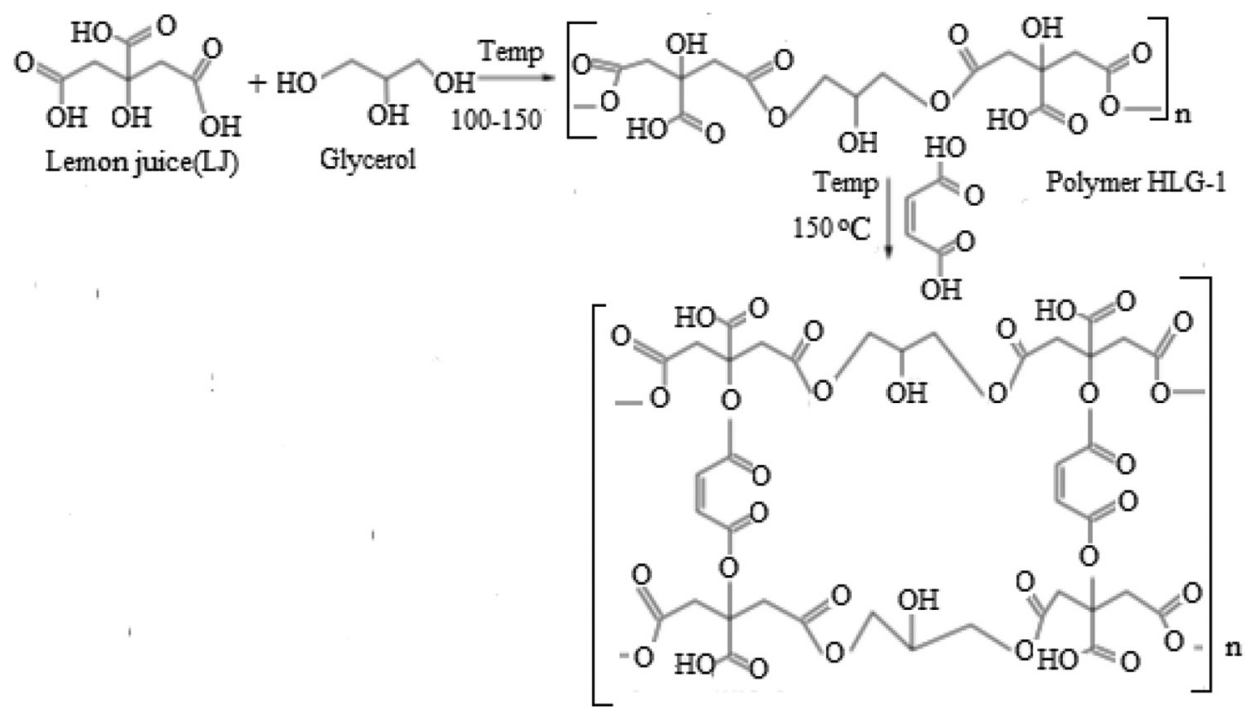

Polymer HLG-2

Figure 1: Diagrammatic scheme of preparation of HLG-2 hydrogel.

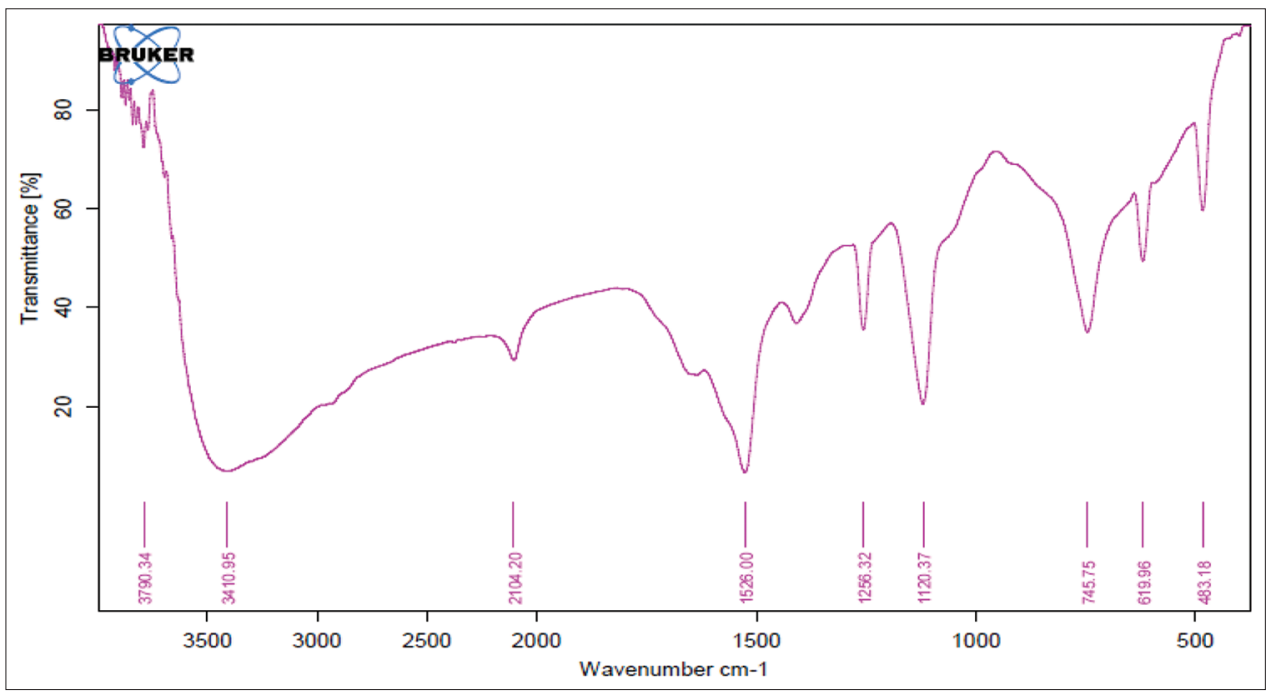

Figure 2: FTIR spectrum of HLG-1 uncross-linked hydrogel.

The absorption peaks observed at around $3790.34 \mathrm{~cm}^{-1}$ are a result of the presence of isolated - $\mathrm{OH}$ groups in lemon juice while the broad peak of $\mathrm{H}-\mathrm{OH}$ appeared at $3410.95 \mathrm{~cm}^{-1}$. The sharp spectra peaks at around $1528 \mathrm{~cm}^{-1}$ and $619.96 \mathrm{~cm}^{-1}$ are assigned to -COO-stretching and $-\mathrm{OH}$ out of plane bend respectively. The peak at $1528 \mathrm{~cm}^{-1}$ assigned to -COO- is a clear indication of the formation of ester linkage between citric acid in lemon juice and glycerol monomers. The peaks at $1256.32 \mathrm{~cm}^{-1}, 1120.37 \mathrm{~cm}^{-1}$, and $745.75 \mathrm{~cm}^{-1}$ are attributed to $\mathrm{C}-\mathrm{O}$ stretching in ether, $\mathrm{C}-\mathrm{O}$ stretch in alky, and C-H out of plane bending respectively.

Figure 3 shows the IR spectrum of the HLG-2 super hydrogel upon crosslinking with maleic acid. Broadband at $3338.55 \mathrm{~cm}^{-1}$ could be attributed to the overlap peaks of $-\mathrm{OH}$ group stretching in citric acid with a strong $\mathrm{H}$ bonded peak observed at around $2934.41 \mathrm{~cm}^{-1}$ in glycerol. In addition, a peak at around $1706.30 \mathrm{~cm}^{-1}$ is associated with $\mathrm{C}=\mathrm{O}$ carbonyl stretching in $\alpha$ and $\beta$ unsaturated aldehyde in the hydrogel network. The bands appearing at $1399.85 \mathrm{~cm}^{-1}, 1339.36 \mathrm{~cm}^{-1}$, and $1323.24 \mathrm{~cm}^{-1}$ are attributed to tertiary - $\mathrm{OH}$ bending in alcohol, primary - $\mathrm{OH}$ in-plane bending and secondary - $\mathrm{OH}$ in-plane bending respectively (Coma et al., 2003). Sharp small peaks appeared at around $1073.19 \mathrm{~cm}^{-1}, 994.20 \mathrm{~cm}^{-1}$ associated with -COO-symmetric stretching and $\mathrm{C}-\mathrm{O}-\mathrm{C}$ bending. The spectra band observed at $1591.34 \mathrm{~cm}^{-1}$ is a result of the presence of -COO- asymmetric stretching associated with successful ester crosslinking between $-\mathrm{OH}$ in the polymeric unit (HCG-1) and -COOH group in the maleic acid binder.

\section{The phase composition of HLG-1 and HLG-2 hydrogels}

Figure 4 and 5 shows the powdered diffraction patterns of the uncross linked HLG-1 and crosslinked HLG-2 hydrogel 


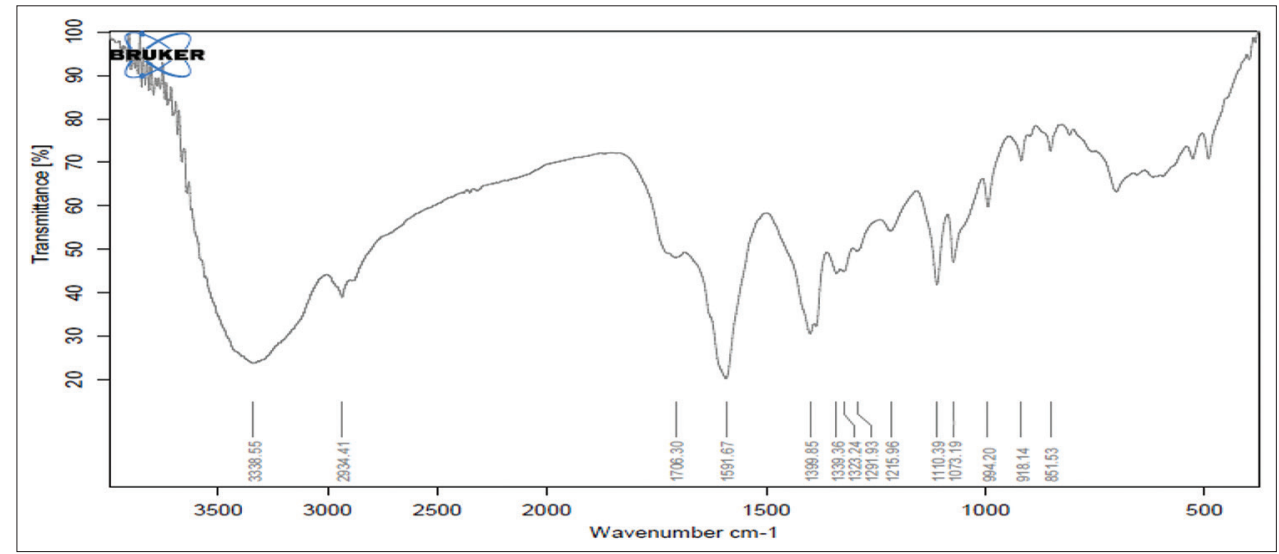

Figure 3: FT-IR spectrum of HLG-2 cross-linked hydrogel.

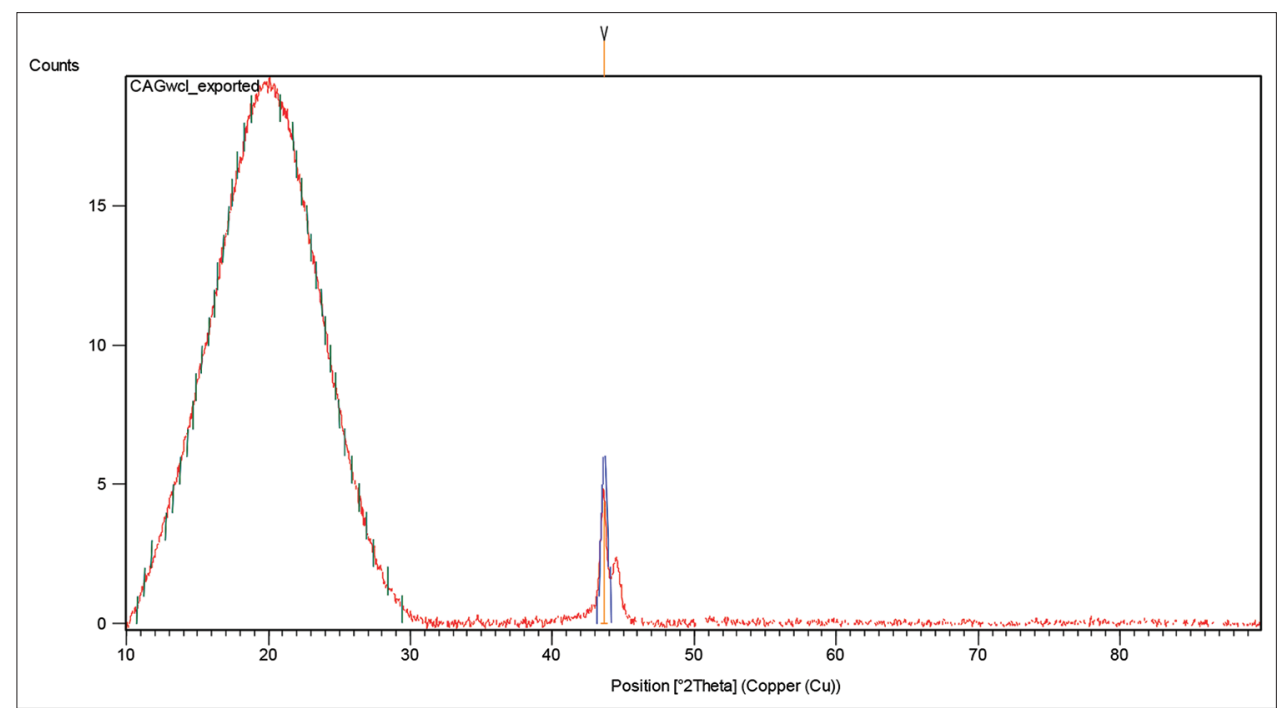

Figure 4: Powdered diffraction pattern of uncross linked HLG-1.

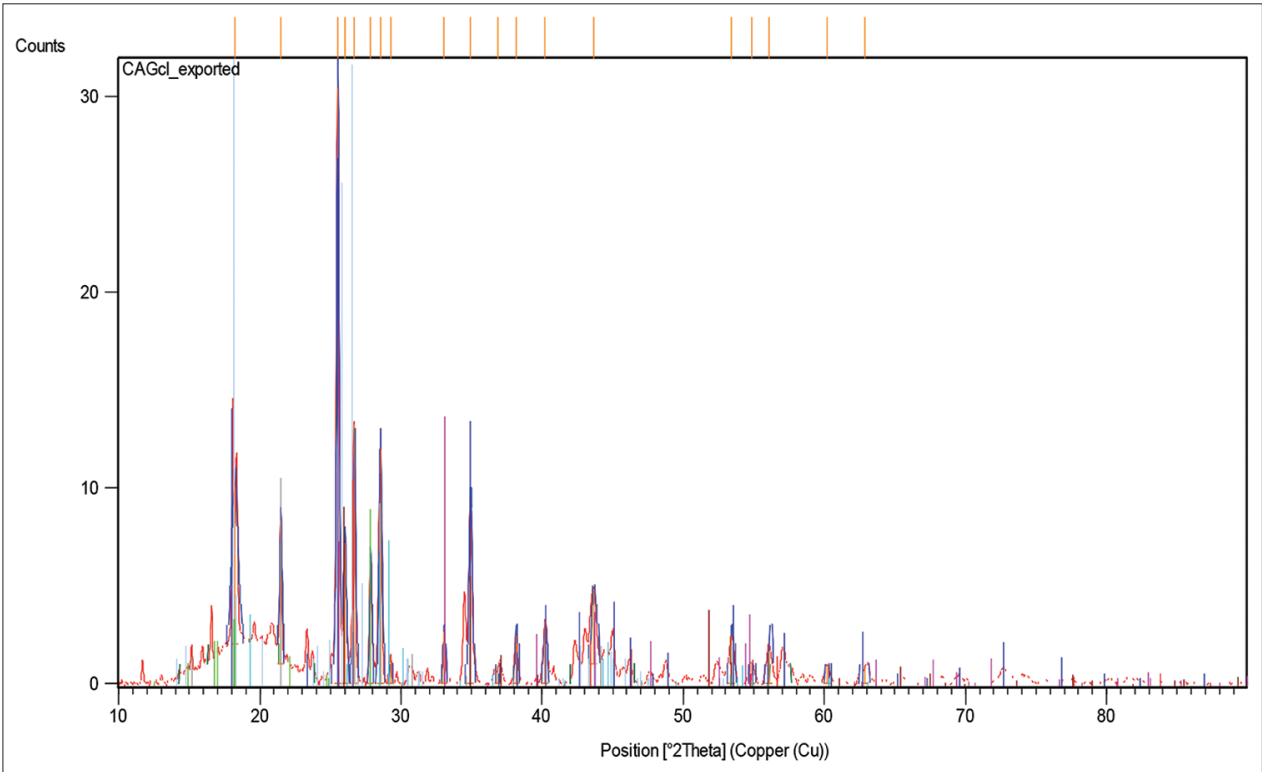

Figure 5: Powdered diffraction pattern of cross-linked HLG-2. 
respectively. The amorphous characteristics of uncross linked HLG-1 hydrogel is highly noticeable due to presence of broad halo peak at angle between 11-31 (20) (Varaprasad et al., 2010). The XRD analysis shows that theHLG-1 hydrogel is mainly amorphous. Upon crosslinking with maleic acid, the polymeric hydrogel was converted to crystalline as shown in Figure 5.

The crystalline peaks at an angle (2 $2 \theta) 18.21$ and 21.47 were observed due to the presence of carboxylate crystalline phases on the polymer network an indication of the semi-crystalline nature of hydrogel HLG-2 (Mohamood et al., 2018). The peaks appearing at an angle (20) 25.52 and 27.83 were due to the tubular structure of carbon atoms in the hydrogel network of HLG-2 compared to an amorphous structure in HLG-1 (Mohamood et al., 2018). The peaks at (20) of 38.18, 40.19, $53.42,54.88$, and $62.48^{\circ}$ may be attributed to the crystalline phase of carboxylate groups in HLG-2, (Naohara et al., 2017). The peak at $26.68^{\circ}(2 \theta)$ arises due to the tubular structure of carbon atoms in the HLG-2 gel (Naohara et al., 2017). Crosslinking the hydrogel showed conversion of the hydrogel from amorphous to crystalline. The increase in ester linkages upon crosslinking resulted in the formation of a threedimensional crystalline polymer structure with high water absorption capacity (Zhao et al., 2004).

\section{SEM analysis of HLG-1 and HLG-2 superabsorbent hydrogels}

The microstructure and morphological analysis of the superabsorbent hydrogel of HLG-1 and HLG-2 was done using a scanning electron microscope (SEM) (Zeiss supra 60 ) at an accelerating voltage of $2.50 \mathrm{kV}$. The SEM images of powdered hydrogels are shown in figure 6 .

The SEM micrograph in figure 6(A) clearly shows that uncross linked HLG-1 super hydrogel had a rigid and constricted surface compared with rough morphological surfaces with voids throughout its structure in HLG-2. The change in morphology after crosslinking contributes to water absorption properties of HLG-2 green superabsorbent (Karadağ \& Üzüm, 2012). The presence of voids in crosslinked polymeric hydrogel could also account for the increased water absorbing ability of the hydrogel. This was possible due to intermolecular hydrogen bonding or intramolecular hydrogen bonding between the side chains and its backbones in HLG-2 green super hydrogel (Guo et al., 2010).

\section{Effect of lemon juice (LJ) dosage on the swelling capacity of hydrogel (HIG-2)}

Figure 7 shows the percentage swelling obtained when $2.0 \mathrm{~g}$ of prepared hydrogel was immersed in distilled water as described in section 2.8 .

The graph in figure 7 shows that as the dose of (LJ) was increased from $0.9-5.4 \mathrm{~mL}$, the percentage swelling of hydrogel increased from $380 \%$ to $860 \%$, followed by a decrease. The
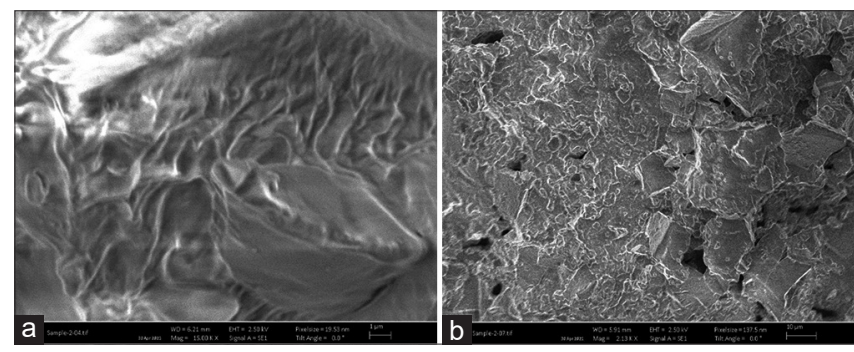

Figure 6: SEM micrographs for (a) uncrosslinked HLG-1 and (b) crosslinked HLG-2 hydrogels.

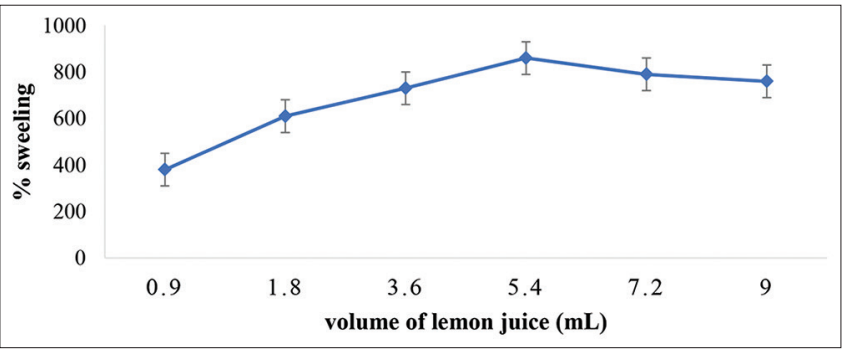

Figure 7: The effect of lemon juice dosage on the percentage swelling of $2.0 \mathrm{~g} \mathrm{HLG}-2$.

increase could be associated with the increased number of anionic hydroxyl groups that led to increased grafting between the functional groups of the monomers forming a crystalline structure (Parvathy \& Jyothi, 2012). Decreased percentage swelling after obtaining optimal swelling capacity could be attributed to the termination of disproportionation reaction instead of coupling as dosage ratio of (LJ) exceeded that of glycerol (Lanthong et al., 2006). A volume of $5.4 \mathrm{~mL}$ of LJ gave a maximum water absorption capacity of $860 \%$.

\section{The effect of maleic acid dosage on the swelling capacity of hydrogel (HLG-2)}

Figure 8 shows the effect of varying dosages of maleic acid cross-linker on the swelling capacity of superabsorbent hydrogel HLG-2.

Figure 8 shows that the percentage swelling of HLG-2 hydrogel increased from 380 to $990 \%$ upon increasing the cross-linker dosage from 1.25 to $3.75 \mathrm{~mL}$. An increase in crosslinker dosage increased the mechanical strength of hydrogel resulting in the formation of smaller well-cross-linked pore networks with increased hydrophilic groups for water absorption (Kabiri et al., 2003). It was also noted that further increase of maleic acid dosage above $3.75 \mathrm{~mL}$ led to a decrease in the percentage swelling capacity. This could be attributed to the fact that an increase in cross-linker dosage above the optimal led to the increased crosslinking density resulting in a rough and rigid network with low water absorption and expansion rate (Kabiri et al., 2003). Incorporation of chemical cross linker in hydrogel preparation improves its mechanical properties as well as the integrity of the gel (Durrani \& Donald, 1995), however, there is a need to determine the 
optimal dosage that will not reduce the swelling capacity of the gel affecting its economic application. A volume ratio of LJ: G: maleic acid (5.4: 3.75: 3.75) was used to prepare HLG-2 gel with optimum swelling capacity.

\section{Effect of contact time on the swelling capacity of the hydrogel}

Figure 9 shows the effect of contact time on the swelling capacity of superabsorbent hydrogel HLG-2 at different contact times.

The percentage swelling of HLG-2 hydrogel increased steadily from $315 \%$ to $910 \%$ with the increase in contact time, from 0.5 to 6 hours followed by a gradual decrease in the rate of swelling to $860 \%$ (Figure 9). Between 0.5 to 6 hours there was an increase in swelling capacity due to increased absorption led by the high number of absorption sites in the hydrogel. An increase in contact time increases the amount of water penetrating the polymer gel through capillary and diffusion in the glassy state and which is absorbed by hydrophilic groups such as carboxylate through the formation of hydrogen bonds (Ji et al., 2018). The swelling is driven by the repulsion of hydrophilic groups inside the network and the osmotic pressure difference in the hydrogel. Above the optimal time of 6 hours, the water absorption rate decreased due to the porous network of the polymer getting saturated hence no vacant spaces for more water molecules (Parvathy \& Jyothi, 2014). Moreover, during the swelling process hydrogels expand and then dissociate releasing acidic molecules in water which decreases water absorption into the functional group ( $\mathrm{Ji}$ et al., 2018).

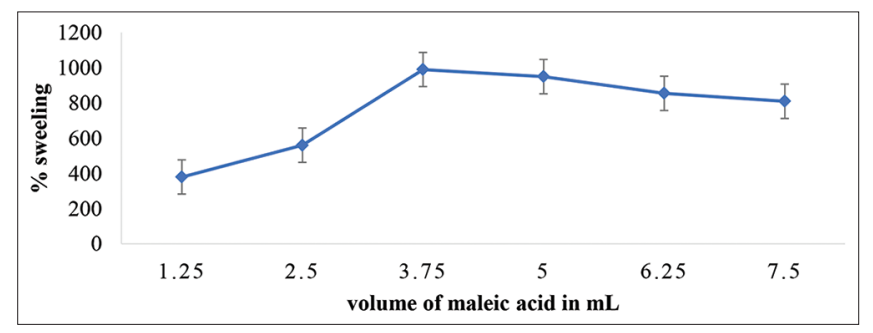

Figure 8: The effect of maleic acid dosage on the percentage swelling of $2.0 \mathrm{~g} \mathrm{HLG}-2$ hydrogel immersed in $500 \mathrm{~mL}$ of distilled water and swelling period of 24 hours.

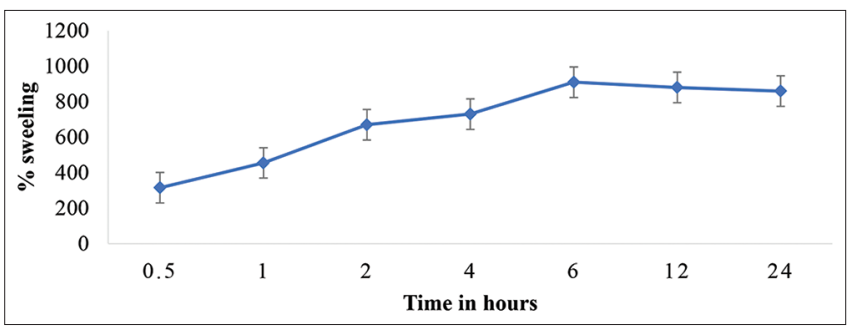

Figure 9: The effect of contact time on the percentage swelling of $2.0 \mathrm{~g}$ HLG-2 hydrogel prepared at optimum conditions reacting volume LJ: G: maleic acid of (5.4: 3.75: 3.75) immersed in $500 \mathrm{~mL}$ of distilled water.

\section{CONCLUSIONS}

The FT-IR spectra showed a band at $1528 \mathrm{~cm}-1$ and $1591.34 \mathrm{~cm}-1$ associated with -COO-stretching indicating successful ester linkage during polymerization and the crosslinking process. XRD analysis showed the conversion of amorphous polymeric material to crystalline. The SEM analysis of HLG-1 showed rigid, rough, and constricted surfaces compared with rough morphological surfaces with clear pores throughout its structure in HLG-2. The results showed that the use of lemon juice, glycerol, and maleic acid in the volume ratio of 5.4: 3.75: 3.75 respectively produced hydrogel with a maximum swelling capacity of $910 \%$ when immersed in water for 6 hours. The high swelling capacity of the cross-linked hydrogel provides a potential application in agriculture especially in semi-arid and arid regions to boost food production.

\section{Acknowledgements}

The authors are grateful to the department of chemistry of Kenyatta University and department of science technology and engineering of Kibabii University for the support during the research period.

\section{Declaration of interest}

The authors declare no conflict of interest on the work described in this study.

\section{REFERENCES}

Aikawa, K., Matsumoto, K., Uda, H., Tanaka, S., Shimamura, H., Aramaki, Y., \&Tsuchiya, S. (1998). Hydrogel formation of the $\mathrm{pH}$ response polymer polyvinylacetal diethylaminoacetate (AEA). International Journal of Pharmaceutics, 167(1-2), 97-104. https://doi.org/10.1016/S0378-5173(98)00057-X

Çöle, G., Gök, M., \& Güçlü, G. (2013). Removal of basic dye from aqueous solutions using a novel nanocomposite hydrogel: N-vinyl 2-pyrrolidone/itaconic acid/organo clay. Water Air Soil Pollution, 224(1760), 1-16. https://doi.org/10.1007/ s11270-013-1760-5

Coma, V., Sebti, J., Pardon, P., Pichavant, F., \& Descahmps, A. (2003). Film properties from crosslinking of cellulosic derivatives with a polyfunctional carboxylic acid. Carbohydrate Polymers, 51(3), 265-271. https://doi.org/10.1016/S0144-8617(02)00191-1

Coolman, R., Kanamori, T., \& Kim, T. (2008). Biodegradable Polymers: Investigating the Reaction between Tartaric Acid and Glycerol, Oregon State University.

Dalaran, M., Emik, S., Güçlü, G., İyim, T., \& Özgümüş, S. (2011). Study on a novel polyampholyte nanocomposite superabsorbent hydrogels: Synthesis, characterization and investigation of removal of indigo carmine from aqueous solution. Desalination, 279(1-3), 170-182. https://doi.org/10.1016/j.desal.2011.06.004

Dalaran, M., Emik, S., Güçlü, G., İyim, T. B., \& Özgümüş, S. (2009). Removal of acidic dye from aqueous solutions using poly (DMAEMA-AMPSHEMA) terpolymer/MMT nanocomposite hydrogels. Polymer Bulletin, 63(2), 159-171. https://doi. org/10.1007/s00289-009-0077-4 
Durrani, C. M., \& Donald, A. M. (1995). Physical characterization of amylopectin gels. Polymer Gels and Networks, 3(1), 1-27. https://doi.org/10.1016/0966-7822(94)00005-R

Guo, X. L., Shi, H. S., \& Dick, W. A. (2010). Compressive strength and microstructural characteristics of class $\mathrm{C}$ fly ash geopolymer. Cement and Concrete Composites, 32(2), 142-147. https://doi. org/10.1016/j.cemconcomp.2009.11.003

Hammond, P., Ali, D., \& Cumming, R. (2005). A system on chip digital $\mathrm{pH}$ meter for use in a wireless diagnostic capsule. Biomedical Engineering, 52(4), 687-694. https://doi.org/10.1109/ TBME.2005.844041

Ji, H., Song, X., Shi, Z., Tang, C., Xiong, L., Zhao, W., \& Zhao, C. (2018). Reinforced-Concrete Structured Hydrogel Microspheres with Ultrahigh Mechanical Strength, Restricted Water Uptake, and Superior Adsorption Capacity. ACS Sustainable Chemical \& Engineering, 6(5), 5950-5958. https://doi.org/10.1021/ acssuschemeng.7b04323

Kabiri, K., Omidian, H., Hashemi, S. A., \& Zohuriaan-Mehr, M. J. (2003). Synthesis of fast-swelling superabsorbent hydrogels: effect of crosslinker type and concentration on porosity and absorption rate. European Polymer Journal, 39(7), 1341-1348. https://doi.org/10.1016/S0014-3057(02)00391-9

Karadağ, E., \& Üzüm, Ö. (2012). A study on water and dye sorption capacities of novel ternary acrylamide/sodium acrylate/PEG semi IPN hydrogels. Polymer Bulletin, 68(5), 1357-1368. https:// doi.org/10.1007/s00289-011-0635-4

Koetting, M., Peters, J., Steichen, S., \& Peppas, N. (2015). Stimulusresponsive hydrogels: Theory, modern advances, and applications. Material Science Engineering Research, 93, 1-49. https://doi.org/10.1016/j.mser.2015.04.001

Lanthong, P., Nuisin, R., \& Kiatkamjornwong, S. (2006). Graft copolymerization, characterization, and degradation of cassava starch-g-acrylamide/itaconic acid superabsorbents. Carbohydrate Polymers, 66(2), 229-245. https://doi. org/10.1016/j.carbpol.2006.03.006

Meng, Y., \& Ye, L. (2017). Synthesis and swelling property of superabsorbent starch grafted with acrylic acid/2-acrylamido2-methyl-1-propanesulfonic acid. Journal of the Science of Food and Agricultural, 97(11), 3831-3840. https://doi.org/10.1002/ jsfa. 8247

Mohamood, N., Zainuddin, N., Ahmad, M., \& Tan, S. (2018). Preparation, optimization and swelling study of carboxymethyl sago starch (CMSS)-acid hydrogel. Chemical Central Journal,

\section{2, 133. https://doi.org/10.1186/s13065-018-0500-8}

Naohara, R., Narita, K., \& Ikeda-Fukazawa, T. (2017). Change in hydrogen bonding structures of a hydrogel with dehydration. Chemical Physics Letters, 670, 84-88. https://doi.org/10.1016/j. cplett.2017.01.006

Parvathy, P. C., \& Jyothi, A. N. (2012). Synthesis, characterization and swelling behaviour of superabsorbent polymers from cassava starch-graft-poly(acrylamide). Starch-Starke, 64(3), 207-218. https://doi.org/10.1002/star.201100077

Parvathy, P., Jyothi, A., John, K., \& Sreekumar, J. (2014). Cassava Starch Based Superabsorbent Polymer as Soil Conditioner: Impact on Soil Physico-Chemical and Biological Properties and Plant Growth. Clean-Soil Air Water, 42(11), 1610-1617. https:// doi.org/10.1002/clen.201300143

Rimmer, S. (2011). Biomedical Hydrogels: Biochemistry, manufacture and medical applications. Cambridge: Woodhead Publishing Limited.

Selling, G., Utt, K., Finkenstadt, V., Kim, S., \& Biswas, A. (2015). Impact of Solvent Selection on Graft Co-polymerization of Acrylamide onto Starch. Journal of Polymers and the Environment, 23(3), 294-301. https://doi.org/10.1007/s10924-015-0714-y

Shukla, N., Rattan, S., \& Madras, G. (2012). Swelling and DyeAdsorption Characteristics of an Amphoteric Superabsorbent Polymer. Industrial \& Engineering Chemistry Research, 51, 14941-14948. https://doi.org/10.1021/ie301839z

Ullah, F., Othman, M., Javed, F., Ahmad, Z., \& Akil, H. (2015). Classification, processing and application of hydrogels. A review. Material Science and Engineering, 57, 414-433. https:// doi.org/10.1016/j.msec.2015.07.053

Varaprasad, K., Mohan, Y., Ravindra, S., Reddy, N., Vimala, K., Monika, K., Sreedhar, B., \& Raju, K. (2010). Hydrogel-silver nanoparticle composites: A new generation of antimicrobials. Journal of Applied Polymer Science, 115, 1199-1207. https://doi. org/10.1002/app.31249

Zhao, Y., Cai, C., Luo, Y., \& He, Z. (2004). FTIR Spectra of the M(EDTA)n- Complexes in the Process of Sol-Gel Technique. Journal of Superconductivity, 17(3), 383-387. https://doi. org/10.1023/B: JOSC.0000034263.79799.02

Zhu, S., Wang, J., Yan, H., Wang, Y., Zhao, Y., Feng, B., Duan, K., \& Weng, J. (2017). An injectable supramolecular self-healing biohydrogel with high stretchability, extensibility and ductility, and a high swelling ratio. Journal of Materials Chemistry B, 5, 7021. https://doi.org/10.1039/C7TB01183K 